doubtedly present in the form of SnO, requiring $4.73 \% \mathrm{O}$. Considering the small amount of substance which was available for these determinations, and also the difficulties involved in the separation of the constituents, the results obtained agree quite well with the calculated percentages. These correspond to the formula $\mathrm{SnCl}_{2} . \mathrm{SnO}$.

The writer is inclined to believe that his determination of the tin was a little too low, rather than assuming that some of this tin was present in the stannic form. In spite of diligent search no reference to the existence of an anhydrous stanno-oxychloride could be found in the literature of the subject.

The occurrence of tin in the burial places of the aborigines will doubtless by discusser by Mr. Moore when he publishes his investigation of the Florida mounds. It is difficult to account for the formation of the chloride inside of a mass of metallic tin, unless we assume that some chloride solution had access to the hollow interior through an opening at the surface.

Perladelphia, Pa.

[CONTRIBUTION FROM THE IOWA AGRICULTURAL EXPERIMENT STATION.]

\title{
THE USE OF SODIUM PARATUNGSTATE IN THE DETER- MINATION OF METALLIC OXIDES FROM CYANIDES.
} By S. B. Kuzirian.

Received June 25, 1917.

The use of sodium paratungstate as a flux capable of completely expelling certain volatile acid radicals in a remarkably short time and conserving the residual oxides in definite and stable form for weighing under ordinary atmospheric conditions has been proposed by Gooch and Kuzirian. ${ }^{1}$ Kuzirian ${ }^{2}$ has further demonstrated the use of this flux in analysis of halogen and oxy-halogen salts. The present work has to do with the extension of the use of the same flux to include cyanides. The commercial sodium cyanide, labelled C. P., when treated with hydrochloric acid and evaporated to dryness in a good draft hood, left a dirty reddish residue, indicating the presence of iron and other impurities. It was therefore discarded. When, however, potassium cyanide that had been packed in a tin can and labelled $99 \%$ pure was likewise treated, it left a white residue. This sample was therefore taken for the analytical experiments with sodium paratungstate. This commercial product when analyzed gravimetrically yielded an average of $0.9460 \mathrm{~g}$. of silver cyanide per half gram sample. When titrated with o. I $N$ silver nitrate, using Liebig's method, an exact check of the gravimetric method was obtained,

${ }^{1}$ Am. J. Sci., 3I, 497 (IgrI).

2 Ibid., 36, 301 (1913). 
indicating absence of chlorides in the commercial product. When total nitrogen was run according to Dumas' method, a $0.5 \mathrm{~g}$. sample yielded 0.0990 g., or $19.8 \%$ nitrogen. This, upon calculation to potassium cyanide, gives an exact check to the gravimetric and volumetric analyses of the commercial product. When two samples of I g. each of the cyanide, after treatment with hydrochloric acid, were evaporated to dryness and ammonium salts volatilized, the resulting chlorides weighed I.1365 g. One of these resulting products was dissolved in water and diluted to $200 \mathrm{cc}$. Two $25-\mathrm{cc}$. aliquot portions of this gave $0.2765 \mathrm{~g}$. AgCl. Hill's ${ }^{1}$ aniline perchlorate method applied to another two aliquot portions of 25 cc. each for the gravimetric estimation of potassium gave $0.25 \mathrm{IO} \mathrm{g}$. of potassium perchlorate which is within the experimental error of the method used. According to the above analysis, therefore, the commercial product was $92 \%$ potassium cyanide and $8 \%$ of some other potassium salt which, upon treatment with hydrochloric acid, was easily converted into potassium chloride. On treatment with dilute sulfuric acid, I $\mathrm{g}$. of this commercial potassium cyanide gave $\mathrm{x} .323 \mathrm{~g}$. of potassium sulfate with bubbling out of some carbon dioxide. It is plain, therefore, that the $8 \%$ impurity in this commercial product was potassium carbonate.

When $\mathrm{o}$. I g. of this commercial potassium cyanide was mixed in a porcelain crucible with sodium paratungstate and the mixture fused with a low flame, considerable action took place and a larger loss than the theoretical resulted. This was due to reduction of the tungstic acid as indicated by the color of the melt in the crucible. The experiment was then repeated in the presence of an oxidizing agent. For this purpose ammonium nitrate was chosen because of the fact that it leaves no weighable residue after fusion with the paratungstate. It was first tried in thin porcelain crucibles-the results obtained were found satisfactory; then it was deemed safe to use platinum. It was the general practice to weigh the platinum crucible with cover, introduce $2-3 \mathrm{~g}$. of the paratungstate, ${ }^{2}$ and weigh again, add a weighed amount of potassium cyanide and finally some dry, powdered ammonium nitrate. The contents were now mixed with the aid of a platinum wire, taking care to brush back any adhering particles, and a low flame played underneath the crucible and finally a low flame applied for a moment or two, until no more gas escaped. It was now cooled in a sulfuric acid desiccator and weighed. The gain in weight of the crucible and paratungstate represented residual metallic oxides. Following are some of the results obtained:

${ }^{1}$ D. U. Hill, Am. J. Sci., 40, 75 (19r5).

${ }^{2}$ The crucible containing the paratungstate alone, after the first weighing was heated below fusion, cooled, and weighed again to insure complete drying. 
JAMES BROWN.

\begin{tabular}{|c|c|c|c|c|c|}
\hline $\begin{array}{l}\text { No. of } \\
\text { experiment. }\end{array}$ & $\begin{array}{l}\text { Wt. of com- } \\
\text { mercial KCN } \\
\text { taken, } \mathrm{g} .\end{array}$ & $\begin{array}{c}\mathrm{K}_{2} \mathrm{O} \\
\text { found, } \mathrm{g} .\end{array}$ & $\begin{array}{l}\text { Theory for } \mathrm{K}_{2} \mathrm{O} \text { on } \\
92 \% \mathrm{KCN} \text { and } 8 \% \\
\mathrm{~K}_{3} \mathrm{CO} \text { basis, } \mathrm{g} .\end{array}$ & Error in g. & Error in \%. \\
\hline I & 0.1490 & 0.1075 & 0.1073 & +0.0002 & +0.19 \\
\hline 2. & .0 .1128 & 0.0808 & 0.0812 & -0.0004 & -0.49 \\
\hline $3 \ldots$. & . . 0.1389 & 0.0995 & 0.0998 & +0.0003 & +0.3 \\
\hline $4 \ldots$ & .0 .2198 & 0.1574 & o. 1572 & +0.0002 & +0.13 \\
\hline $5 \ldots$ & 0.2708 & o. 1942 & 0.1936 & +0.0006 & +0.31 \\
\hline
\end{tabular}

Carbonates, nitrates and iodides lose their acid radicals on gentle heating with this flux. Cyanides, as seen from the above table, do the same in the presence of an oxidizing agent. Other halogens, when suspected of being present in commercial cyanides, will leave a definite and weighable oxide on the application of a small blowpipe flame. ${ }^{1}$ This flux may therefore be applied with advantage for the estimation of residual basic oxides in cyanides which are weighed with the flux.

AMEs, IOWA.

[CONTRIBUtion From the Chemical LaboRatory of Butler UNIVERsity.]

\section{THE USE OF CUPFERRON (PHENYLNITROSO-HYDROXYL- AMINE AMMONIUM) IN: I. THE QUANTITATIVE SEPARA- TION OF ZIRCONIUM, TITANIUM, IRON, MANGANESE AND ALUMINUM. II. THE ANALYSIS OF ZIRCON AND BADDELEYITE.}

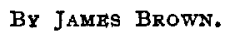

Received July 2, 1917.

The work described in this paper was undertaken with the purpose of ascertaining the applicability of the cupferron reagent to the analysis of zirconium minerals. The minerals investigated thus far have been samples of zircon and baddeleyite purchased in powdered form from a mineral dealer. A preliminary analysis showed the zircon to consist of silica, zirconium, titanium, iron and aluminum. The baddeleyite was found to consist of the same elements as the zircon, plus small amounts of manganese and water. Baudisch ${ }^{2}$ has shown that cupferron may be used as a quantitative precipitant for iron, and the iron determined by ignition to the oxide. His work has been confirmed by several investigators. Baudisch also separated iron from manganese by the use of cupferron in the analysis of minerals. Bellucci and Grassi ${ }^{3}$ have shown the cupferron reagent to be a quantitative precipitant for titanium, and that this element can thereby be separated quantitatively from aluminum in acid solution. Thornton and Hayden ${ }^{4}$ have found that cupferron may also be used in separating titanium from aluminum and phosphoric acid

\footnotetext{
1 Kuzirian, Am. J. Sci., 36, 30г (1913).

${ }^{2}$ Chem. Ztg., 33, 1293-1300 (1909).

${ }^{3}$ Gazz. chim. ital., 43, I, 570 (1913).

${ }^{4}$ Am. J. Sci., [4] 37, I73 (1914).
} 